\title{
A highly ordered, nonprotective MALAT1 ENE structure is adopted prior to triplex formation
}

\author{
MICHAEL J. YONKUNAS and NATHAN J. BAIRD \\ Department of Chemistry \& Biochemistry, University of the Sciences, Philadelphia, Pennsylvania 19104, USA
}

\begin{abstract}
The $3^{\prime}$ end of the 7 kb IncRNA MALAT1 contains an evolutionarily and structurally conserved element for nuclear expression (ENE) which confers protection from cellular degradation pathways. Formation of an ENE triple helix is required to support transcript accumulation, leading to persistent oncogenic activity of MALAT1 in multiple cancer types. Though the specific mechanism of triplex-mediated protection remains unknown, the MALAT1 ENE triplex has been identified as a promising target for therapeutic intervention. Interestingly, a maturation step of the nascent IncRNA $3^{\prime}$ end is required prior to triplex formation. We hypothesize that disruption of the maturation or folding process may be a viable mechanism of inhibition. To assess putative cotranscriptional ENE conformations prior to triplex formation, we perform microsecond MD simulations of a partially folded ENE conformation and the ENE triplex. We identify a highly ordered ENE structure prior to triplex formation. Extensive formation of $U \bullet U$ base pairs within the large U-rich internal loops produces a global rod-like architecture. We present a three-dimensional structure of the isolated ENE motif, the global features of which are consistent with small angle X-ray scattering (SAXS) experiments. Our structural model represents a nonprotective conformation of the MALAT1 ENE, providing a molecular description useful for future mechanistic and inhibition studies. We anticipate that targeting stretches of $U \bullet U$ pairs within the ENE motif will prove advantageous for the design of therapeutics targeting this oncogenic IncRNA.
\end{abstract}

Keywords: ENE; molecular dynamics; RNA dynamics; small angle X-ray scattering; IncRNA

\section{INTRODUCTION}

RNAs arising from noncoding regions comprise roughly two-thirds or more of the human genome (Woo 2018). A growing number of long noncoding RNA (IncRNA) actively alter gene expression and promote cellular dysfunction in cancer cells (Arun et al. 2018). Regulation of IncRNA transcripts is not fully understood but is thought to follow a deadenylation-dependent degradation pathway (Conrad et al. 2006; Thompson and Parker 2007; Geisler et al. 2012; Tycowski et al. 2012). Uniquely, several viral and mammalian IncRNAs, including those without a canonical poly(A) tail, maintain high transcript levels by evading degradation (Conrad et al. 2006; Brown et al. 2012; Tycowski et al. 2012, 2016; Wilusz et al. 2012). An evolutionarily conserved RNA element for nuclear expression (ENE) near the $3^{\prime}$ ends of these transcripts confers stability. This ENE motif functions as a cis-acting RNA stability element and has been identified across diverse genomes including viruses, plants, fungi, and mammals (Tycowski et al. 2016). Reports indicate stabilization of both IncRNA and mRNA transcripts by the ENE motif, which leads to evasion of cellular degra-

Corresponding author: n.baird@usciences.edu

Article is online at http://www.rnajournal.org/cgi/doi/10.1261/rna. 069906.118. dation pathways, resulting in high levels of transcript accumulation in the nucleus and cytoplasm (Wang et al. 1999; Conrad and Steitz 2005; Muhlrad and Parker 2005; Conrad et al. 2006; Garneau et al. 2008; Brown et al. 2012; Wilusz et al. 2012). The protective function of the ENE is dependent on formation of a triplex between a large U-rich internal loop and the transcript 3' A-rich tail (MittonFry et al. 2010; Brown et al. 2012; Wilusz et al. 2012). Sequestration of the $3^{\prime}$ end within the triplex precludes degradation in vitro (Ageeli et al. 2018). Two ENE triplex crystal structures have revealed the RNA $3^{\prime}$ end embedded within a triple helical architecture (Mitton-Fry et al. 2010; Brown et al. 2012). The ENE triplex is further stabilized by stacking atop canonical duplexes forming a continuous duplex-triplex-duplex structure.

The IncRNA MALAT1 is overexpressed in many human cancer types (Ji et al. 2003; Lin et al. 2007; Lai et al. 2012) and high transcript levels are dependent on the protective ENE triplex (Brown et al. 2012; Wilusz et al. 2012).

\footnotetext{
(c) 2019 Yonkunas and Baird This article is distributed exclusively by the RNA Society for the first 12 months after the full-issue publication date (see http://rnajournal.cshlp.org/site/misc/terms.xhtml). After 12 months, it is available under a Creative Commons License (Attribution-NonCommercial 4.0 International), as described at http:// creativecommons.org/licenses/by-nc/4.0/.
} 
Maturation of IncRNA MALAT1 involves cleavage of a tRNA-like domain on the $3^{\prime}$ end of the nascent MALAT1 transcript by RNase $P$ followed by formation of the ENE triplex with the matured A-rich tail. The speed of processing and triplex formation is not precisely known, but the dynamic interconversion between an isolated ENE and a well-formed triplex regulates in vitro degradation (Ageeli et al. 2018). Because the nuclear abundance of the oncogenic MALAT1 is regulated by the ENE triplex, this small 94-nt protective element may be a viable drug target (Brown et al. 2012). Furthermore, the crystal structure of the MALAT1 ENE triplex supports direct structure-function relationship studies. Overall, the small size of the MALAT1 ENE triple helix $\left(\mathrm{M} 1^{\mathrm{TH}}\right)$ is readily tractable by both experimental and computational methods, facilitating detailed investigations of triplex-mediated RNA protection and the discovery of potential inhibitory mechanisms to ameliorate cancer progression supported by MALAT1.

Singular structures do not define RNA functions in cells; the interplay between alternate conformations determines RNA function and ultimately cellular regulation (Russell et al. 2002; Mahen et al. 2005; Wickiser et al. 2005; Dethoff et al. 2008; Serganov and Nudler 2013; Saldi et al. 2018). With the discovery of an increasing number of IncRNAs connected to cancer and neurobiological dysfunction (Johnsson and Morris 2014; Huarte 2015; Arun et al. 2018), targeting cotranscriptional structures using high-throughput screening is increasing in popularity (Ganser et al. 2018). In fact, owing to the exceptional thermostability of $\mathrm{M}^{\mathrm{TH}}$ following triplex formation (Brown et al. 2012; Ageeli et al. 2018), targeting cotranscriptional structures of the MALAT1 ENE may represent a feasible approach to drug discovery, where at minimum, a putative highly ordered structure of the isolated ENE motif may become the focus of therapeutic interventions. Several questions remain unanswered regarding putative cotranscriptional structures of the ENE motif prior to triplex formation. Specifically, the absence of the A-rich tail may render the large U-rich internal loop devoid of structure or may bring the U-rich regions in close proximity to form nonnative interactions. The functional implications of either structural arrangement have not been adequately investigated. Previous reports suggest residual structure within the U-rich internal loop. A temperature-dependent peak in the NMR spectrum of an isolated ENE motif, lacking the triplex-forming A-rich sequence, was implicated in formation of $U \bullet U$ pairs within the U-rich loop (Mitton-Fry et al. 2010). Similarly, UV melt analysis of the isolated ENE motif indicates residual structure within the U-rich regions (Ageeli et al. 2018).

Here we directly investigate the structure and dynamics of the MALAT1 ENE triplex core ( $\mathrm{M} 1_{\text {core }}^{\mathrm{TH}}$ ) and a partially folded ENE conformation ( $\mathrm{M} 1_{\text {partial }}^{\mathrm{TH}}$ ) using microsecond molecular dynamics (MD) simulations. We present a quan- titative description of the ENE motif structure prior to triplex formation. Limited structural flexibility within the ENE results from highly ordered $U \bullet U$ pairs between the U-rich regions. Small angle X-ray scattering (SAXS) experiments confirm the global properties of our simulated ENE motif structure. Importantly, our results provide a molecular description of a nonprotective conformation of the MALAT1 ENE prior to triplex formation (Ageeli et al. 2018), the structure of which represents a putative target for therapeutic intervention.

\section{RESULTS}

The $3^{\prime}$ terminus of the nascent MALAT1 transcript forms a tRNA-like domain. A requisite maturation step is required to form the protective triple helix. Cleavage of the tRNAlike domain by RNase $P$ produces the mature $3^{\prime}$ A-rich tail and subsequent formation of the triplex (Brown et al. 2012; Wilusz et al. 2012; Ageeli et al. 2018), comprising stretches of five and four $\mathrm{U} \bullet A-U$ triples interrupted by $a$ $\mathrm{C}^{+} \bullet \mathrm{G}-\mathrm{C}$ triplet and a G-C doublet (Fig. 1A,B; Brown et al. 2012; Wilusz et al. 2012). To better understand the molecular underpinnings guiding triplex formation, we performed all-atom MD simulations. Although folding of RNAs can occur on the single microsecond timescale (Hyeon and Thirumalai 2012; Hori et al. 2018), robust folding pathways require millisecond simulations. Because millisecond all-atom simulations of monitoring folding of RNAs of this size are currently not accessible, we performed comparative analyses of two different structural models of the MALAT1 triplex: (i) a structural model representing the native, functional structure of the triplex core, defined by a crystal structure (PDBID:4PLX) (Brown et al. 2012), which we refer to herein as $M 1_{\text {core }}^{\mathrm{TH}}$ (Fig. $\left.1 A, B\right)$ and (ii) a partially folded structure wherein the A-rich tail is not hybridized with the ENE, referred to as $\mathrm{M} 1 \mathrm{TH}$ partial (Fig. 1C). We generated the initial $M 1_{\text {partial }}^{\mathrm{TH}}$ structural model by rotating the $3^{\prime}$ A-rich tail (3'-tail) away from the ENE core (Fig. 1C). We reasoned that this arrangement of the tail represents a conformation that may generally describe the ENE motif and $3^{\prime}$ tail structures after maturation by RNase $P$ and prior to formation of the triplex. Our initial $M 1_{\text {partial }}^{\mathrm{TH}}$ structural model treats the ENE and $3^{\prime}$ tail as independent structural regions within a single transcript. We use this structural model to evaluate dynamic structural changes that may occur after RNase $P$ maturation, rather than immediately before triplex formation. Importantly, we anticipate that movements of the unstructured $3^{\prime}$ tail may be influenced by nucleotides within the linker. Therefore, in an effort to represent $\mathrm{M} 1_{\text {partial }}^{\mathrm{TH}}$ in a more biologically relevant conformation space, we replaced the truncated linker sequence present in the crystal structure with the wild-type human MALAT1 sequence, which we modeled as an ideal A-form helix (see Materials and Methods). Thus, the $\mathrm{M}_{\text {partial }}^{\mathrm{TH}}$ structure contains 15 linker 
A

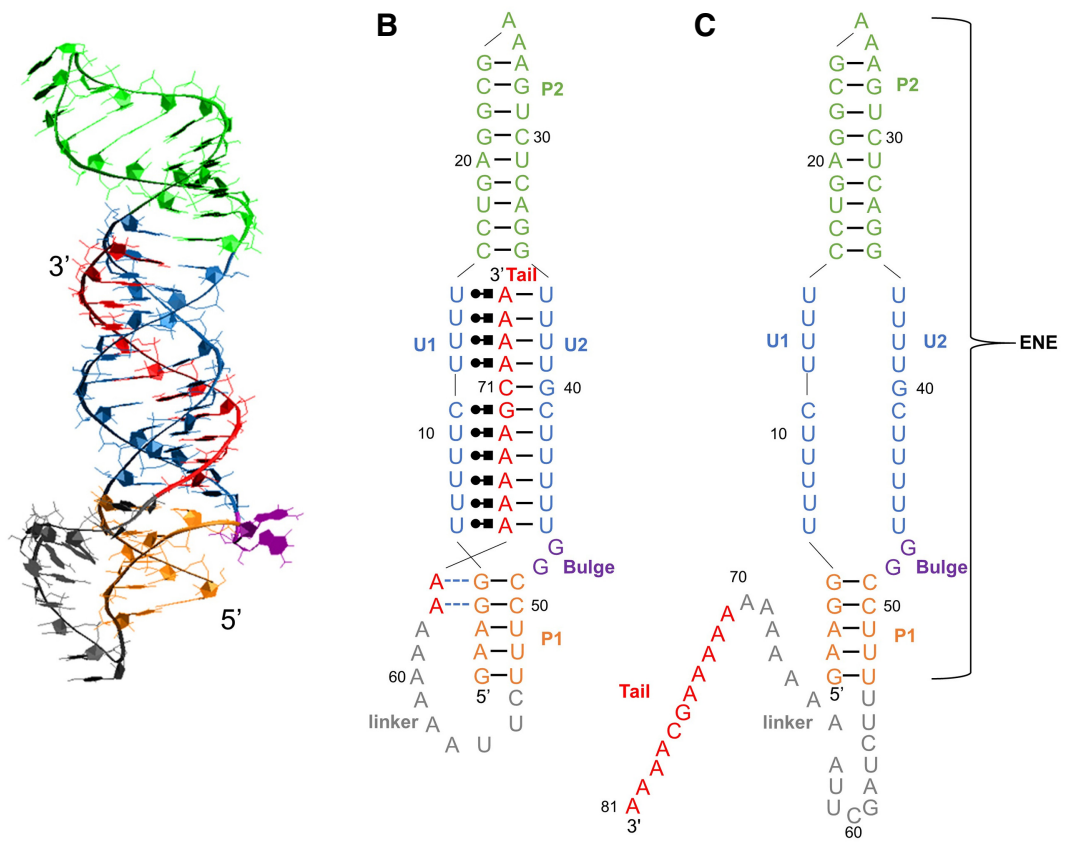

FIGURE 1. $M 1^{\mathrm{TH}}$ secondary and tertiary structure. The tertiary structure $(A)$ and secondary structure $(B)$ of $M 1^{\mathrm{TH}}$ (PDBID:4PLX) shown as a ribbon representation and secondary structure diagram, respectively. Each color corresponds to a structural element where the P1 helix is orange, the $\mathrm{U}$-rich regions $\mathrm{U} 1$ and $\mathrm{U} 2$ are blue, the $\mathrm{P} 2$ helix is green, the bulge nucleotides are purple, the linker region is gray, and the $3^{\prime}$ tail is red. (C) The secondary structure diagram of a disrupted $3^{\prime}$ strand $\mathrm{M}^{\mathrm{TH}}$ model $\left(\mathrm{M} 1_{\text {partial }}^{\mathrm{TH}}\right)$ is shown using the same structural element coloring as in $B$.

nucleotides, six additional nucleotides relative to the $\mathrm{M} 1_{\text {core }}^{\mathrm{TH}}$. Overall, the starting structural models of $\mathrm{M} 1_{\text {partial }}^{\mathrm{TH}}$ and $\mathrm{M} 11_{\text {core }}^{\mathrm{TH}}$ have identical atomic coordinates for nucleotides 1-53 (crystallographic numbering), which comprise the ENE core (Fig. 1C). Structural distinctions between the initial models are confined between nucleotide 54 and the $3^{\prime}$ end of the RNA.
Intrinsic global dynamics of $\mathrm{M} 1_{\text {core }}^{\mathrm{TH}}$ and $\mathrm{M} 1_{\text {partial }}^{\mathrm{TH}}$

MD simulations of both $M 1_{\text {core }}^{\mathrm{TH}}$ and $\mathrm{M} 1_{\text {partial }}^{\mathrm{TH}}$ were monitored using RMSD of backbone atoms aligned and compared to the final equilibrated structure over simulation time at an increment of 2 psec per frame (see Materials and Methods). From a 1.2 $\mu$ sec simulation of each RNA system, the RMSD of $M 1_{\text {core }}^{\mathrm{TH}}$ (Fig. 2, black line) and $\mathrm{M}_{\text {partial }}^{\mathrm{TH}}$ (Fig. 2, red line) was calculated over an 800 and 760 nsec equilibrium trajectory, respectively (see Materials and Methods). The $\mathrm{M} 1$ core ${ }_{\text {co }}^{\mathrm{TH}}$ average RMSD of $5 \AA$ (Fig. 2A) is consistent with simulations of nonribosomal RNAs of similar size (Réblová et al. 2006; Priyakumar and MacKerell 2010; Huang et al. 2013; Aytenfisu et al. 2015; Suresh et al. 2016). The $\mathrm{M} 11_{\text {partial }}^{\mathrm{TH}} \mathrm{RMSD}$ fluctuates between 15 and $30 \AA$ during the first $100 \mathrm{nsec}$ (Fig. 2A). After this initial period of fluctuating structure, $\mathrm{M} 1_{\text {partial }}^{\mathrm{TH}}$ continues with RMSD $\sim 18 \pm 4 \AA$ over the course of the simulation. Large fluctuations would be expected for a partially folded RNA, though the global RMSD analysis does not indicate whether these structural dynamics are equally distributed throughout the $\mathrm{M} 1_{\text {partial }}^{\mathrm{TH}}$ structure. To address this, we also evaluated the RMSD for nucleotides 1-53, which constitute the ENE motif in both $\mathrm{M}_{\text {core }}^{\mathrm{TH}}$ and $\mathrm{M} 1_{\text {partial }}^{\mathrm{TH}}$ (Fig. 2A, gray and pink lines, respectively). This comparison highlights the stability of the ENE motif despite the distinct
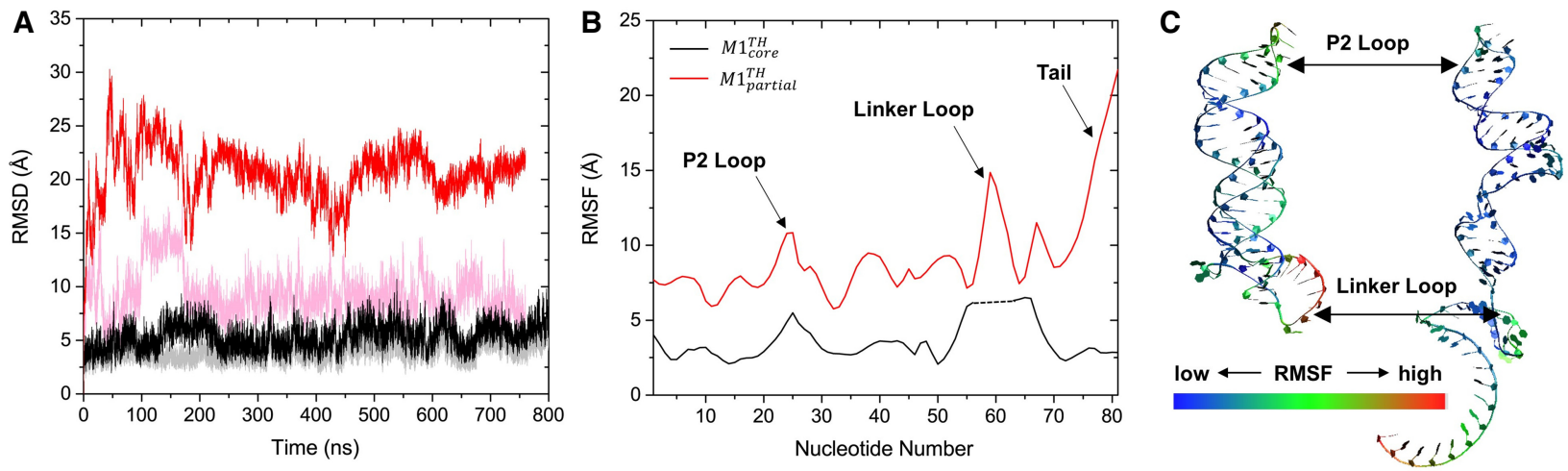

FIGURE 2. Root mean square analysis from MD simulations. (A) RNA backbone RMSD plot of the $M 1_{\text {core }}^{\mathrm{TH}}$ (black line) compared to M1 partial (red line) shows the overall deviations from the starting equilibrated structure. The backbone RMSD of only the ENE motif is shown in gray (M1TH ${ }_{\text {core }}$ ) and pink ( $\mathrm{M} 1_{\text {partial }}^{\mathrm{TH}}$ ). (B) Root mean square fluctuations (RMSF) for $\mathrm{M} 1_{\text {partial }}^{\mathrm{TH}}$ (red) and $\mathrm{M} 1_{\text {core }}^{\mathrm{TH}}$ (black). The $\mathrm{P} 2$ helix and linker loop exhibit high fluctuations in both simulations while the $3^{\prime}$ tail fluctuates in $\mathrm{M} 1_{\text {partial }}^{\mathrm{TH}}$ but not in $\mathrm{M} 1_{\text {core }}^{\mathrm{TH}}$. A dotted line represents the truncated sequence within the $\mathrm{M} 1_{\text {core }}^{\mathrm{TH}}$. (C) RMSF mapped to the $M 1_{\text {core }}^{\mathrm{TH}}$ and $\mathrm{M} 1_{\text {partial }}^{\mathrm{TH}}$ structural models according to a color scale from low (blue) to high (red). 
RNA structures. While the $\mathrm{M} 1$ partial $\mathrm{THE}$ motif (light pink) makes a conformational transition at the 100-150 nsec time frame (Fig. 2A), large increases in RMSD of the total $\mathrm{M} 1_{\text {partial }}^{\mathrm{TH}}$ structure (red) can be primarily attributed to dynamics of the linker (54-70) and the $3^{\prime}$ tail (71-81), which are both peripheral to the ENE core (Supplemental Fig. S1). Overall, the RMSD calculations clearly indicate a globally dynamic behavior for $\mathrm{M} 1_{\text {partial }}^{\mathrm{TH}}$ and a globally static behavior for $\mathrm{M} 1_{\text {core }}^{\mathrm{TH}}$.

To assess the degree of local fluctuations in the structure, we calculated the root mean square fluctuation (RMSF) by comparing the RNA backbone for each trajectory frame to the average structure from the last $800 \mathrm{nsec}$ of simulation. In contrast to RMSD, the RMSF provides average dynamic information at the single nucleotide scale. The RMSF for $\mathrm{M}_{\text {core }}^{\mathrm{TH}}$ (black line) and $\mathrm{M} 1_{\text {partial }}^{\mathrm{TH}}$ (red line) are shown on the same nucleotide axes (Fig. 2B), where a dashed line indicates the truncated region of the $M 1_{\text {core }}^{\mathrm{TH}}$ linker (Fig. 1B,C). The fluctuations in the $\mathrm{M} 1_{\text {partial }}^{\mathrm{TH}}$ structure are overall larger than $\mathrm{M}_{\text {core }}^{\mathrm{TH}}$. Using the lowest fluctuation for each simulation as a respective normalization ( $\sim 4 \AA$ for $\mathrm{M} 1_{\text {core }}^{\mathrm{TH}}$ and $\sim 8 \AA$ for $\mathrm{M} 1_{\text {partial }}^{\mathrm{TH}}$, Supplemental Fig. S1), we evaluated specific regions of heightened flexibility between the two simulated RNAs. This comparison reveals reduced fluctuations in the U-rich strands (Fig. 1B,C) of $\mathrm{M} 1_{\text {partial }}^{\mathrm{TH}}$ relative to $\mathrm{M} 1_{\text {core }}^{\mathrm{TH}}$ (Supplemental Fig. S1). The contrasting relative fluctuation within these regions is surprising because this region is specifically involved in a three-stranded triplex in $\mathrm{M} 1_{\text {core }}^{\mathrm{TH}}$ but a heretofore unknown structure in $\mathrm{M} 1_{\text {partial }}^{\mathrm{TH}}$. In fact, there are only three regions where $\mathrm{M} 1_{\text {partial }}^{\mathrm{TH}}$ exhibits a higher relative fluctuation compared to $\mathrm{M} 1_{\text {core }}^{\mathrm{TH}}$ : the $5^{\prime}$ portion of $\mathrm{P} 2$ (near nucleotide 15), the $3^{\prime}$ region of $\mathrm{P} 1$ (near nucleotide 50 ), and the $3^{\prime}$ A-rich tail (Fig. 2B; Supplemental Fig. S1). The increased fluctuation within P1 and P2 are localized to initial regions of the duplex-triplex junctions due to local structural rearrangements upon removal of the $3^{\prime}$ tail. Increased fluctuations within the $3^{\prime}$ tail are expected given the single-stranded nature of this region in $\mathrm{M} 1$ partial. Mapping the raw fluctuations (Fig. 2B) to the surface of each structure gives a view of the flexibility differences between $M 1_{\text {core }}^{\mathrm{TH}}$ and $\mathrm{M} 1_{\text {partial }}^{\mathrm{TH}}$ (Fig. 2C). Although our simulations demonstrate large increases in both RMSD and RMSF for $\mathrm{M}_{\text {partial, }}^{\mathrm{TH}}$, structural dynamics are limited to the single-stranded $3^{\prime}$ tail rather than indicative of multiple transiently populated conformations.

\section{The $M 1_{\text {partial }}^{\mathrm{TH}}$ ENE motif forms distinct local interactions}

Over the time-scale of our simulation $\mathrm{M} 1$ partial does not fold into a triplex conformation, nor does $\mathrm{M} 1_{\text {core }}^{\mathrm{TH}}$ dissociate into an unfolded conformation. To assess convergence of our simulations, we use the RMS average correlation function (RAC) (Galindo-Murillo et al. 2015), where a RAC value of $0 \AA$ A represents a completely converged time-series data set (see Supplemental Methods). Convergence values of $<0.6 \AA$ and $0.1 \AA$ for $M 1_{\text {core }}^{\mathrm{TH}}$ and $\mathrm{M} 1_{\text {partial }}^{\mathrm{TH}}$, respectively, were calculated (Supplemental Fig. S2). The 90\% convergence value of the $\mathrm{M} 1_{\text {partial }}^{\mathrm{TH}}$ simulation occurs more quickly than the $\mathrm{M} 1_{\text {core }}^{\mathrm{TH}}$ simulation, demonstrating the structural integrity of our $\mathrm{M}_{\text {partial }}^{\mathrm{TH}}$ system. We quantitatively assess each trajectory using a 2D RMSD- $R_{\mathrm{g}}$ coordinate space, where $R_{\mathrm{g}}$ represents the radius of gyration, comparing the global motion and overall size for each RNA (Supplemental Fig. S3). Overall, the $M 1_{\text {core }}^{\mathrm{TH}}$ and $\mathrm{M} 1_{\text {partial }}^{\mathrm{TH}}$ simulations are stable around a single minimum, where structural variations are attributed to global stretching or compression dynamics (Supplemental Fig. S4; Supplemental Information).

Not surprisingly, the $\mathrm{M} 1_{\text {core }}^{\mathrm{TH}}$ triplex structure is highly stable (Supplemental Fig. S3A), consistent with systematic UV melt and FRET experiments demonstrating stable triplex formation across a broad range of multiplexed monovalent and $\mathrm{MgCl}_{2}$ solution conditions (Ageeli et al. 2018). To assess the level of local structural variations for the simulated $\mathrm{M} 1_{\text {core }}^{\mathrm{TH}}$, we quantify the fraction of specific base pair interactions $\left(f_{\mathrm{bp}}\right)$ over simulation time (see Materials and Methods), represented on a per nucleotide basis using a heat map (Fig. 3A). Local variations near the G40-C71 base pair are quite dynamic. Specifically, U10 (U1) interacts with $A 68$ and $A 69$ (Tail) equivalently over simulation time. Additionally, aside from interacting with their cognate base-pairing partners, U8 and U9 in the U1 region interact with nucleotides A67 and A66 (Tail), respectively, for $>20 \%$ of simulation time. These interactions constitute alternative base-pairings or "slippage" and suggest conformational dynamics in the center of the triplex. Regardless, the primary interactions within the triplex region are base-triple interactions between the Tail (nt. 65-75), U2 (nt. 36-46) and U1 (nt. 6-15). Direct interactions between $U 1$ and $U 2$ are minimal ( $<6 \%$ of simulation time). Unfolding of the triplex or dissociation of the $3^{\prime}$ tail does not occur during $\mathrm{M} 1$ core ${ }_{\text {com- }}^{\mathrm{TH}}$ ulation. Therefore, this interaction map is consistent with a well-formed triplex, and is supported by experimental analysis wherein the triplex is resistant to $3^{\prime}-5^{\prime}$ exoribonuclease degradation (Ageeli et al. 2018).

Previous studies have suggested that the internal loop within the $U 1$ and $U 2$ regions of the isolated ENE motif is highly flexible (Conrad and Steitz 2005; Conrad et al. 2006; Mitton-Fry et al. 2010; Brown et al. 2012; Tycowski et al. 2012, 2016; Donlic et al. 2018). Structural plasticity within this region would result in a dynamic, partially collapsed RNA exhibiting minimal, or highly transient, interactions involving $U 1$ and $U 2$ regions. To assess structural interactions, or lack thereof, within the U-rich regions of the ENE, we calculate $f_{b p}$ for the $M 1_{\text {partial simulation }}^{\mathrm{TH}}$ (Table 1; Fig. 3B). This quantitative description of base pair interactions within the $\mathrm{M} 1_{\text {partial }}^{\mathrm{TH}}$ ENE motif reveals a significantly altered fingerprint when compared to $\mathrm{M} 1_{\text {core }}^{\mathrm{TH}}$ (Fig. 3A). The loss of triplex interactions involving the 

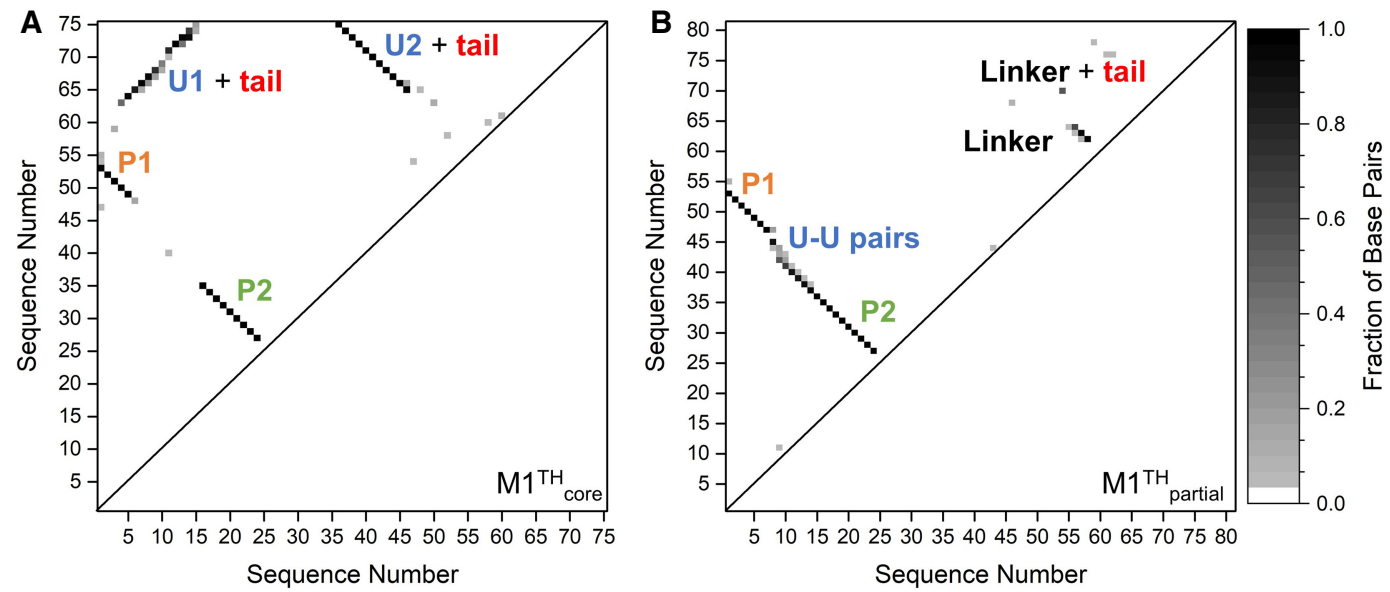

FIGURE 3. Fraction of base pairs $\left(f_{\mathrm{bp}}\right)$ observed during MD simulations. The $f_{\mathrm{bp}}$ interactions for each nucleotide are presented as a grayscale heat map for (A) $\mathrm{M}_{\text {core }}^{\mathrm{TH}}$ and $(B) \mathrm{M}_{\text {partial. }}^{\mathrm{TH}}$. Each heat map represents a fingerprint for highly stable base pairs (black) and transient base pairs (lighter gray) throughout the MD simulation. Regions of interest are labeled with text and colored according to the structural diagrams shown in Figure 1.

duplex strand (U2), Hoogsteen strand (U1), and the $3^{\prime}$ tail (Tail) are expected, though it is informative to note that their occupancy remains near zero for the duration of the simulation. One new region of interaction is clearly formed during simulation of $\mathrm{M}_{\text {partial }}^{\mathrm{TH}}$ (Fig. 3B); our analysis reveals a high degree of base pair interactions within the U-rich regions. The types of base pair interactions observed on average in the newly formed U1-U2 region from the $\mathrm{M} 1$ partial simulation are listed in Table 1 and are consistent with cisWatson-Watson interactions (cWW, Leontis-Westhof notation) observed in antiparallel RNA strands (Leontis and Westhof 2001). However, the first $U \bullet U$ pair between U8 and $U 45$ is dominated by a trans-Watson-Watson interaction $69 \%$ of the time and a trans-Sugar-Watson interaction $10 \%$ of the time. The most dynamic nucleotide in the region, U9, interacts with U42, U43, and U44 in a cisWatson-Watson configuration ranging from $13 \%$ to $55 \%$ of simulation time. The majority of remaining $U \bullet U$ pairs are present in cis-Watson-Watson for $>99 \%$ of simulation time. This new U1-U2 duplex is formed of primarily $U \bullet U$ base pairs (Fig. 4A,B), some of which exhibit a high degree of alternative base-pair interactions. We depict the alternative pair interactions observed during MD simulations on the secondary structure of $\mathrm{M}_{\text {partial }}^{\mathrm{TH}}$ (Fig. 4C), where a solid blue arrow indicates the highest populated interaction (typically $f_{\mathrm{bp}}>80 \%$ ) and a dotted arrow indicates transient interactions $\left(10 \%<f_{b p}<20 \%\right)$. Formation of the $U \bullet U$ pairs leads to a highly ordered backbone structure in which the phosphate-phosphate distances are decreased relative to a standard A-form duplex (Fig. 4D).

Our analysis indicates for the first time that the ENE maintains a significantly ordered structure, rather than adopting highly dynamic, flexible conformations as previously suggested. Our simulation results imply specific structures are maintained within the U-rich regions $\mathrm{U} 1$ and U2. To determine whether such structure can be experimentally corroborated, we performed SAXS experiments to compare the global structural properties of the RNA in solution with the properties of our simulated structure (see Materials and Methods). The calculated $R_{\mathrm{g}}$ of our simulated ENE is in excellent agreement with experimental SAXS results (Table 2). The experimental $R_{\mathrm{g}}$ for the isolated ENE motif is $27.6 \pm 0.6 \AA$; the calculated $R_{\mathrm{g}}$ from our simulated ENE structure is $27 \AA$. Additionally, comparison of the probability distribution, or $P(r)$, profiles from experiment and simulation (Supplemental Fig. S5) indicates that both structures are extended, mostly rod-like, with an identical maximum distance $\left(D_{\max }\right)$, within error (Table 2$)$. We attribute small differences in the probability distributions between experimental and simulated ENE motifs to differences in solvation layers between calculated and experimental systems as well as possible over-winding of the $M 1_{\text {partial }}^{\text {TH }}$ structure induced by the MD force-field. Overall, both the simulated and experimental ENE structures maintain a markedly extended conformation, rather than a collapsed structure. Given that MD simulations of $M 1_{\text {partial }}^{\mathrm{TH}}$ result in a highly ordered ENE structure represented by a single conformational minimum, we reasoned that internal structure within the U-rich regions would be necessary to achieve such stability.

\section{A nonprotective conformation of the MALAT1 ENE}

Based on the MD-derived high probability base pairs within $\mathrm{M} 1_{\text {partial }}^{\mathrm{TH}}$, we present a new $\mathrm{M} 1_{\text {partial }}^{\mathrm{TH}}$ secondary structure (Fig. 5A) depicting the structural interactions within the ENE motif, in which well-ordered $U \bullet U$ pairs are defined with $f_{b p}>0.8$ (Fig. 4C). The structure reveals a contiguous double helical stack. This distinct conformation, compared to $\mathrm{M} 1_{\text {core }}^{\mathrm{TH}}$ (Fig. 1B), is a result of rearrangement of the $\mathrm{U} 1$ 
TABLE 1. Average base pair interactions over $800 \mathrm{nsec}$ simulation time

\begin{tabular}{|c|c|c|c|c|}
\hline U1 & U2 & Interaction & $f_{\mathrm{bp}}$ & Leontis-Westhof type \\
\hline 15 & 36 & UU & 99 & cWW \\
\hline 14 & 37 & UU & 99 & $\mathrm{cWW}$ \\
\hline 13 & 38 & UU & 99 & cWW \\
\hline 12 & 39 & UU & 99 & $\mathrm{cWW}$ \\
\hline 11 & 40 & CG & 88 & cWW \\
\hline 10 & 41 & UC & 70 & cWW \\
\hline 10 & 42 & UU & 17 & cWW \\
\hline 9 & 42 & UU & 55 & $\mathrm{cWW}$ \\
\hline 9 & 43 & UU & 13 & $\mathrm{cSW}, \mathrm{cWW}$ \\
\hline 9 & 44 & UU & 19 & $\mathrm{cWW}$ \\
\hline 8 & 45 & UU & 86 & $\mathrm{tSW}, \mathrm{tWW}, \mathrm{cWW}$ \\
\hline 8 & 47 & UG & 17 & $\mathrm{cWW}$ \\
\hline 7 & 47 & UG & 99 & cWW \\
\hline 6 & 48 & UG & 99 & cWW \\
\hline Linker & Linker/Tail & & & \\
\hline 46 & 67 & UA & 86 & Varied \\
\hline 54 & 70 & $A U$ & 55 & tWS \\
\hline 56 & 64 & $A C$ & 65 & $\mathrm{cWH}, \mathrm{tWH}, \mathrm{cWW}$ \\
\hline 57 & 63 & $A U$ & 99 & cWW \\
\hline 58 & 62 & UA & 99 & cWW \\
\hline
\end{tabular}

$f_{b p}$ is the fraction of base pairs observed over simulation time for the $U 1$, $\mathrm{U} 2$, Linker, and Tail regions of $\mathrm{M} 1$ partial as shown in Figure 3B. Types are determined using Leontis-Westhof classification (Leontis and Westhof 2001).

and $\mathrm{U} 2$ strands where predominantly new $\mathrm{U} \bullet U$ base pairs are formed amid two unpaired nucleotides (U43 and U44 on U2).

In light of the very limited interactions between the ENE and adjacent linker and $3^{\prime}$ tail, the ENE motif represents an independent structural domain, comprising only nucleotides 1-53 of our simulated structure. Consequently, we generated an average structure of the ENE motif from the last 500 nsec of production simulation. However, this average ENE structure lacks the wild-type P2 sequence, which was truncated to facilitate crystallization (Fig. 1A, $B)$. Therefore, to achieve a wild-type model of the ENE motif structure, we modeled the wild-type P2 helix as an Aform helix (Fig. 5B). After manually fitting the P2 helix to the apex of the simulated ENE motif structure, the system was re-solvated and equilibrated for 2 nsec to achieve a final structure of the wild-type ENE (Fig. 5C). Theoretical scattering calculations of the wild-type ENE structure (ENE + WT P2) are in excellent agreement with experimental SAXS measurements of the wild-type ENE motif RNA of the same sequence (Table 2; Supplemental Fig. S5). Overall, the SAXS data indicate an extended structure consistent with the elongated duplex-like stack within the ENE + WT P2 structure. It is clear from the new
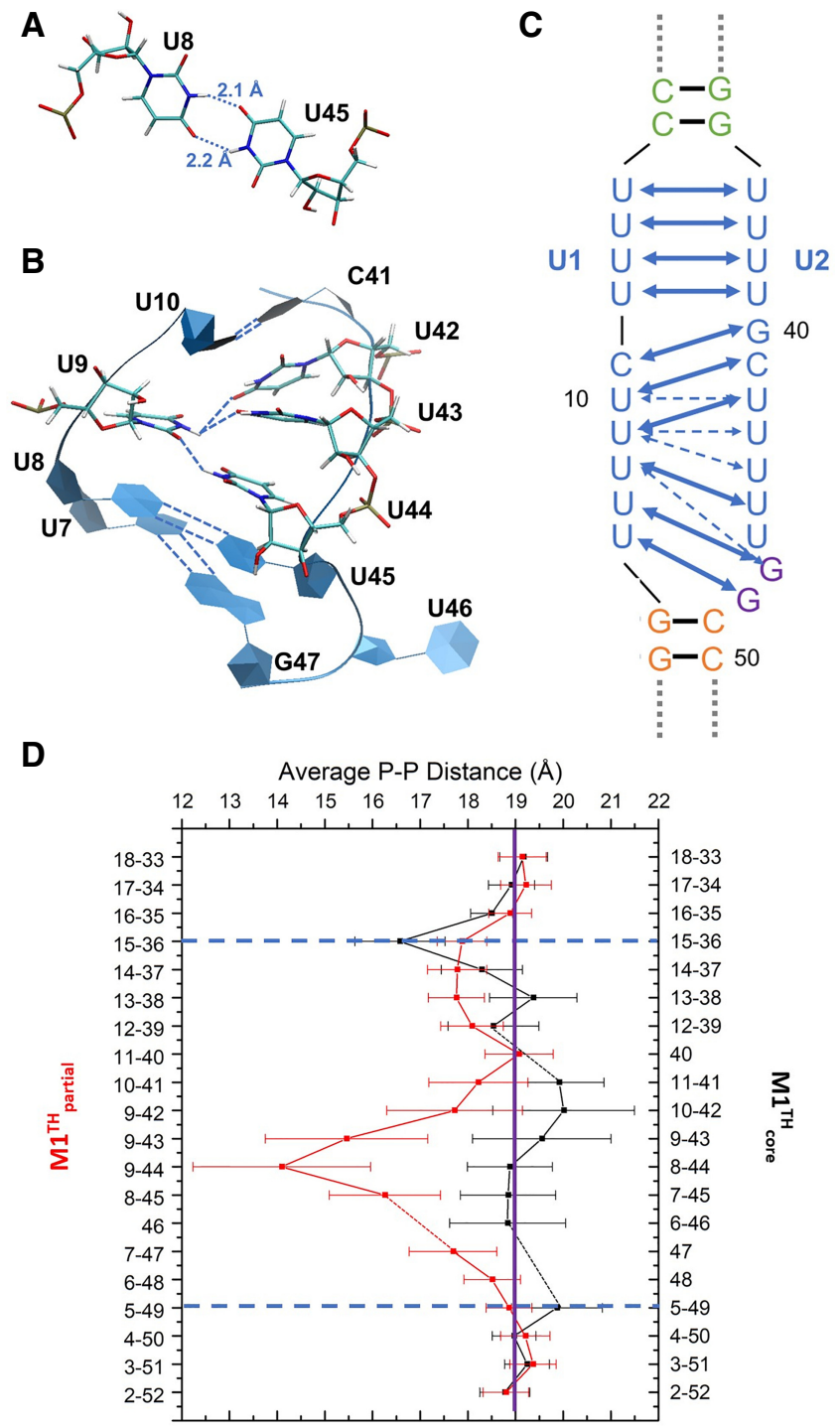

FIGURE 4. Base-pair interactions in the $M 1^{\mathrm{TH}}$ ENE motif. (A) Example of $U \bullet U$ pair observed in $M 1_{\text {partial }}^{\mathrm{TH}}$ simulation at site $\mathrm{U} 8-\mathrm{U} 45$ in a transWatson-Crick interaction. The hydrogen bonds in this base pair are present for more than $86 \%$ of simulation time. (B) A snapshot of a dynamic region within the ENE including nucleotides U7-U10 on U1 and C41-G47 on U2. Blue dotted lines indicate potential hydrogen bonding. This view effectively depicts the promiscuity of $U 9$, which is within reach of U42 ( $\left.f_{\mathrm{bp}} \sim 55 \%\right), \mathrm{U} 43$ ( $f_{\mathrm{bp}} \sim 13 \%$ ), and U44 ( $f_{\mathrm{bp}} \sim 19 \%$ ) (Table 1). (C) Zoomed in partial secondary structure of the ENE motif (Fig. 1C) with $f_{b p}$ (Table 1) mapped to each nucleotide pair where a solid blue arrow indicates the highest populated interaction (typically $f_{\mathrm{bp}}>80 \%$ ) and a dotted arrow indicates transient interactions $\left(10 \%<f_{\mathrm{bp}}<20 \%\right)$. (D) For each base pair detected, the average phosphate-phosphate distance $(P-P)$ was calculated over the MD simulation time. The right axis corresponds to $\mathrm{M} 1_{\text {core }}^{\mathrm{TH}}$ base pairs (black line), and the left axis corresponds to $M 1_{\text {partial }}^{\mathrm{TH}}$ base pairs (red line). Missing values at bulged nucleotides are closed with dotted lines. The horizontal blue dashed lines indicate a structural transition between U1-U2 region with the canonical A-form duplexes (P1 and P2) within each structure. The average phosphate-phosphate distance for helical A-form RNA is indicated by a purple line (van Knippenberg and Hilbers 1986). 

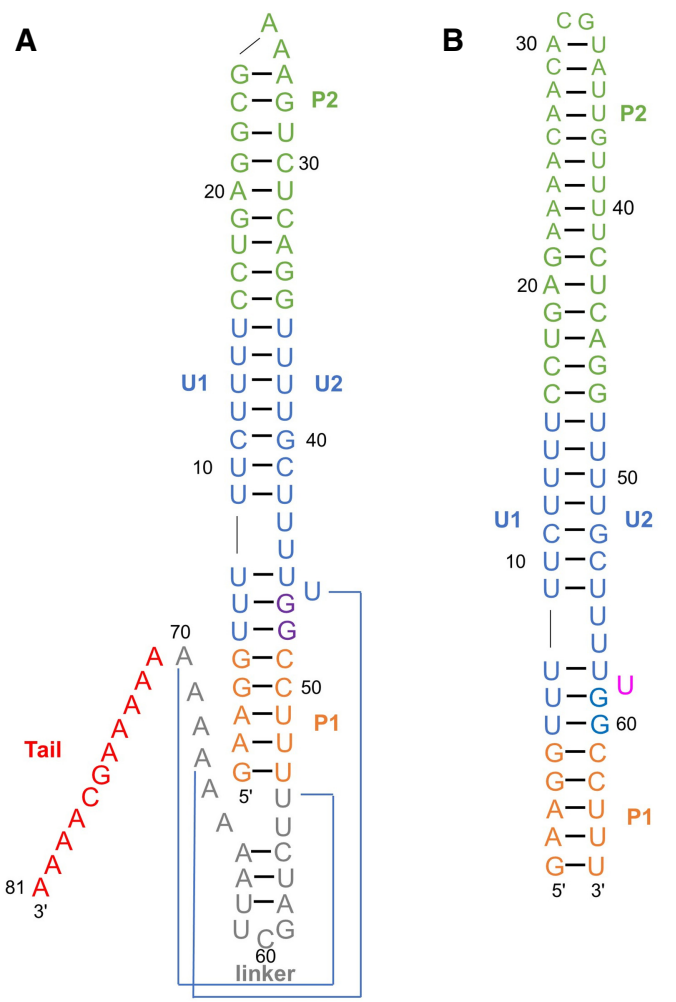

C

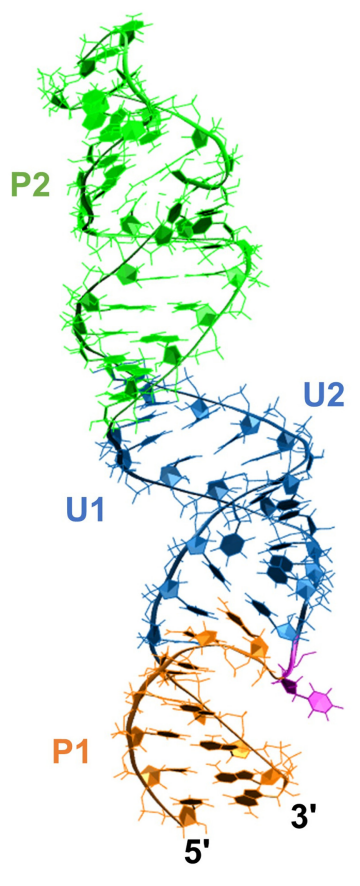

FIGURE 5. A structure of the MALAT1 ENE motif. $(A)$ The secondary structure of the M1 $1_{\text {partial }}^{\mathrm{TH}}$ determined by simulation highlights structure within the $U 1$ and $U 2$ regions; blue lines show through-space tertiary interactions. (B) Secondary structure of the isolated wild-type MALAT1 ENE structure including the full-length P2 helix. (C) Three-dimensional model of wild-type MALAT1 ENE shows a non-A-form helical stack in an extended rod-like conformation consistent with SAXS measurements (Table 2; Supplemental Fig. S5).

structure of the wild-type ENE (Fig. 5C) that the newly formed $U \bullet U$ base pairs tolerate a non-A-form helical conformation (Fig. 4D). Stability of this region is maintained by a well-ordered helical $\cup \bullet U$ stack. This unique topology, while rarely observed experimentally (Baeyens et al. 1995), is highly stable, in contrast to structures containing singular $U \bullet U$ base pairs whose stability is weakened relative to $U \bullet \mathrm{G}$ or $\mathrm{C} \bullet \mathrm{A}$ mismatches (Kierzek et al. 1999; Sheng et al. 2013).

\section{DISCUSSION}

Many biological processes utilize alternative conformers to regulate RNA function (Russell et al. 2002; Mahen et al. 2005; Wickiser et al. 2005; Dethoff et al. 2008; Serganov and Nudler 2013; Saldi et al. 2018). Cotranscriptional RNA folding may populate alternative structures including nonproductive conformations (Hua et al. 2018). For the IncRNA MALAT1, $3^{\prime}$ end maturation by RNase $P$ is a requisite step for proper formation of a protective 3' ENE triplex, which supports high cellular abundance and persistent IncRNA oncogenic processes (Brown et al. 2012; Wilusz et al. 2012). Therefore, a cotranscriptionally folded ENE motif, if highly structured prior to triplex formation, would represent an important nonfunctional structure for therapeutic intervention. Recently, we investigated the mechanism of $\mathrm{M} 1^{\mathrm{TH}}$ triplex formation using a battery of biochemical and biophysical approaches. We determined that prior to liberation of the $3^{\prime}$ end upon RNase P cleavage, a stable P2 and a weak P1 helix are partially formed, suggesting a metastable ENE structure exists prior to triplex formation. (Ageeli et al. 2018). Protection from degradation is conferred through formation of the triplex (Brown et al. 2016; Ageeli et al. 2018). Dynamic structural interconversions between the isolated ENE structure and the well-formed triplex regulate triplex-mediated protection in vitro. Here, we perform microsecond MD simulations to investigate structural variations within the ENE triplex and the isolated ENE motif. We assess the conformational dynamics of the MALAT1 ENE prior to triplex formation, which we refer to as $M 1_{\text {partial. }}^{\mathrm{TH}}$. Our quantitative results support a highly ordered ENE structure comprising nonnative $\mathrm{U} \bullet U$ pairs, leading to an overall extended tructure. The global properties of this ENE structure are supported by SAXS $R_{\mathrm{g}}$ and $P(r)$ data, confirming the extended duplex conformation of the MALAT1 ENE. While the ENE triplex of $\mathrm{M} 1_{\text {core }}^{\mathrm{TH}}$ and isolated ENE of $\mathrm{M} 1_{\text {partial }}^{\mathrm{TH}}$ are identical at the nucleotide level, no tendency to convert between conformations was observed on this timescale. A quantitative assessment of convergence shows a converging trajectory, suggesting both conformations are indeed distinct stable conformational states. Therefore, the stable MALAT1 ENE may be entirely formed cotranscriptionally; prior to $3^{\prime}$ end maturation of the nascent MALAT1 transcript, the two duplexes and U-rich regions form a stable, extended rod-like structure, which is insufficient to protect MALAT1 from $3^{\prime}$ to $5^{\prime}$ exoribonucleolytic degradation. We present the first evidence of a highly ordered ENE motif stabilized by nonnative $U \bullet U$ pairs. This stable ENE structure unveils a novel putative therapeutic target. Recent studies have utilized numerous small molecule designs to target $U \bullet U$ base pairs (Arambula et al. 2009; Xia et al. 2014). Similar efforts targeting the ENE structure may yield effective inhibition of the IncRNA MALAT1. 
TABLE 2. Experimental and theoretical SAXS calculations

\begin{tabular}{lcc}
\hline RNA & $R_{\mathrm{g}}$ & $D_{\max }$ \\
\hline Experimental ENE (WT) & $27.6(0.6)$ & $93(6)$ \\
Simulated ENE (truncated P2) & $23(0.7)$ & $83(3)$ \\
Simulated ENE + WT P2 & $27(1)$ & $92(3)$
\end{tabular}

The radius of gyration $\left(R_{\mathrm{g}}\right)$ and maximum intramolecular distance $\left(D_{\max }\right)$ were determined experimentally using SAXS or calculated from structural models using CRYSOL (Svergun et al. 1995) and GNOM (Svergun 1992). Experimental ENE (WT), wild-type RNA transcript containing the fulllength P2 helix; Simulated ENE (truncated P2), the ENE motif derived from the average structure of the simulated $\mathrm{M} 1_{\text {partial }}^{\mathrm{TH}}$ structure; Simulated ENE + WT P2, a structural model created to include the wild-type (longer) $\mathrm{P} 2$ helix atop the simulated $\mathrm{M} 1_{\text {partial }}^{\mathrm{TH}}$ ENE motif. The differences in $R_{\mathrm{g}}$ and $D_{\max }$ from the experimental ENE (WT) SAXS and the theoretical calculations from simulated ENE (truncated P2) are due to differences in the length of the P2 helix; the simulated structure contains a truncated 6-bp P2 helix compared to the full-length 13-bp helix in the wild-type RNA. By modeling the wild-type $\mathrm{P} 2$ helix onto the simulated $\mathrm{M}_{\text {partial }}^{\mathrm{TH}} \mathrm{ENE}$ motif (simulated ENE + WT P2) we recover $R_{\mathrm{g}}$ and $D_{\max }$ values in agreement with the experimental values. Error in $R_{\mathrm{g}}$ and $D_{\max }$ are indicated in parentheses (see Materials and Methods).

\section{MATERIALS AND METHODS}

\section{Simulation system preparation}

We simulated two different RNA systems, which we refer to as $\mathrm{M} 1_{\text {core }}^{\mathrm{TH}}$ and $\mathrm{M} 1_{\text {partial }}^{\mathrm{TH}}$. The $\mathrm{M} 1_{\text {core }}^{\mathrm{TH}}$ structure includes the triplex region, a truncated P2 helix, and truncated linker sequence. The atomic coordinates for $\mathrm{M}_{\text {core }}^{\mathrm{TH}}$ were obtained from the only available crystal structure of the MALAT1 triplex (Brown et al. 2012). For this study, we used chain A of PDB:4PLX (Brown et al. 2012) with the GTP at position 1 and the modified adenosine at position 76 residues removed. We generated the starting structure for a partially folded $\mathrm{M} 1^{\mathrm{TH}}$, which we refer to as $\mathrm{M} 1_{\text {partial, }}^{\mathrm{TH}}$, by first rotating the $\mathrm{A} 65$ dihedral (A64:O3', $\left.\mathrm{A} 65: \mathrm{P}, \mathrm{A} 65: \mathrm{O5}^{\prime}, \mathrm{A} 65: \mathrm{C} 5^{\prime}\right)$ from chain $A$ by $65^{\circ}$ in the $x$-plane followed by $20^{\circ}$ in the $y$-plane. These manual molecular adjustments resulted in a conformation with the A-rich tail removed from the ENE. Our starting $\mathrm{M} 1_{\text {partial }}^{\mathrm{TH}}$ conformation also includes the wild-type basal linker sequence, which we inserted from position U54 to A70 (Wilusz et al. 2008). These inserted nucleotides were modeled as an ideal A-form RNA helix using the threading module of ROSETTA 3.9 (rosettacommons.org). Molecular modeling and visualization of both RNAs were done using VMD (Humphrey et al. 1996) and the OL3 parameter set for RNA that incorporates modified glycosidic torsion profiles using tleap in AMBERTOOLS16 (Case et al. 2016).

All RNA systems were prepared using tleap within AMBERTOOLS 16 (Case et al. 2016). Each RNA molecule was placed in an explicit solvent TIP3P box with Cartesian dimensions $(116.3,116.3,116.3) \AA$ and $(125.5,63.5,81.4) \AA$, providing a solvent buffer of $10 \AA$ and $8 \AA$ for $M 1_{\text {core }}^{\mathrm{TH}}$ and $\mathrm{M} 1_{\text {partial }}^{\mathrm{TH}}$ systems, respectively. The $M 1_{\text {core }}^{\mathrm{TH}}$ simulation system was neutralized with $74 \mathrm{Na}^{+}$ ions and $\mathrm{M}_{\text {partial }}^{\mathrm{TH}}$ with $80 \mathrm{Na}^{+}$ions. Atoms P, OP1, OP2, O5', $\mathrm{C}^{\prime}, \mathrm{C4}^{\prime}, \mathrm{C3}^{\prime}, \mathrm{O}^{\prime}$ were chosen to describe the RNA backbone and placed under harmonic restraints during minimization and initial equilibration phases. Minimization of each system was conducted by 500 steepest descent steps followed by 9500 conjugate gradient steps, restraining all RNA atoms with a force constant $10 \mathrm{kcal} \mathrm{mol}^{-1} \AA^{-2}$ to remove unfavorable contacts. For all MD simulations conducted in this work: a simulation time step of $2 \mathrm{fsec}$ is used, all bonds involving hydrogen are constrained with SHAKE (Ryckaert et al. 1977), a nonbonded cutoff of $9 \AA$ is used, and the default Particle Mesh Ewald (PME) parameters for Amber are used to handle long-range electrostatics. Heating of each system is done over 3000 steps of canonical (NVT) MD from 100 to $300 \mathrm{~K}$ using a weak coupling thermostat (Berendsen et al. 1984) at constant pressure. Next, 500 psec of NVT MD equilibration were performed using the above RNA backbone restraints at a constant temperature of $300 \mathrm{~K}$ using a weak coupling thermostat (Berendsen et al. 1984). Five, 2 nsec stages of equilibration are performed using NPT MD, maintained at $300 \mathrm{~K}$ using Langevin dynamics with a collision frequency of $3 \mathrm{psec}^{-1}$, and at constant pressure maintained by a Berendsen barostat. Each stage uses a position restrained RNA backbone where the restraints are gradually released over each equilibration stage from an initial force constant of $10 \mathrm{kcal} \mathrm{mol}^{-1} \AA^{-2}$ to a final force constant of $0.5 \mathrm{kcal}$ $\mathrm{mol}^{-1} \AA^{-2}$. Production unrestrained equilibrium NPT MD simulations were performed on a single Linux machine utilizing NVIDIA P2000 GPU cards running PMEMD CUDA in AMBER 16 (Case et al. 2016). The $M 1_{\text {core }}^{\mathrm{TH}}$ system was simulated for $1.2 \mu \mathrm{sec}$. The $\mathrm{M} 1_{\text {partial }}^{\mathrm{TH}}$ system was simulated for $1 \mu \mathrm{sec}$. Approximately, 800 nsec of equilibrium MD from each simulation system was used in subsequent analyses as determined by RMSD calculations. Translational and rotational motions were removed from the trajectory by fitting all frames to the first frame of the analysis data set using CPPTRAJ in AMBERTOOLS 16 (Case et al. 2016).

The root mean square deviation (RMSD) was calculated as

$$
\operatorname{RMSD}=\left[\frac{1}{N} \sum_{i=1}^{N} n_{i}\left|\boldsymbol{r}_{i}(t)-\boldsymbol{r}_{i}^{\text {ref }}(t)\right|^{2}\right]^{1 / 2},
$$

where $N=\sum_{i}^{n}, r_{i}(\mathbf{t})$ are the coordinates of atom i at time $t$ after fitting to the reference coordinates $r_{i}^{\text {ref }}(\boldsymbol{t})$, for which the first frame of production simulation was used. The root mean square fluctuation (RMSF) was calculated per nucleotide as

$$
\operatorname{RMSF}=\left[\frac{1}{T} \sum_{t_{j}=1}^{T}\left|\boldsymbol{r}_{i}\left(t_{j}\right)-\overline{\boldsymbol{r}_{i}}\right|^{2}\right]^{1 / 2},
$$

where $T$ is the time and $\bar{r}_{i}$ is the average position of particle $i$ over $T$.

\section{Fraction of base pairs}

Base pairs were identified using the DSSR package (Lu et al. 2015) of the 3DNA program (Lu and Olson 2003). All MD trajectories were read into DSSR using the -nmr flag, all 29 base pair references were searched at every frame using the -more option and output as a JSON formatted file. Analyses were performed using custom R ( $R$ Core Team 2018) scripts. The fraction of base pair, $f_{b p}$, is calculated as

$$
f_{\mathrm{bp}}=\frac{N_{\mathrm{bp}}}{N}
$$

where $N_{b p}$ is the number of frames in a simulation a base pair is observed, and $N$ is the total number of frames in the simulation. Heat map plots were constructed using R (R Core Team 2018). 


\section{Small angle X-ray scattering experiments}

In vitro transcription of the wild-type isolated ENE motif was performed using PCR templates containing two $2^{\prime} \mathrm{OMe}$ at the $5^{\prime}$ end of the template strand as previously described (Ageeli et al. 2018). The sequence of the isolated ENE motif is GGAAGGTTTTTCTTTTCCTGAGAAAACAACACGTATTGTTTTC TCAGGTTTTGCTTTTTGGCCTTT. Samples were purified by sizeexclusion chromatography in $20 \mathrm{mM}$ HEPES, pH 7.4, $150 \mathrm{mM}$ $\mathrm{NaCl}$ and $\mathrm{KCl}$, and $1 \mathrm{mM} \mathrm{MgCl}_{2}$. Data were collected under continuous flow on beamline ID-12 at the Advanced Photon Source (APS) at Argonne National Laboratories, controlled and collected using beamline-specific programs and scripts. Data was collected for buffer samples and RNA samples separately. Igor Pro (WaveMetrics) was used to examine data quality. A Guinier analysis was used to calculate $R_{\mathrm{g}}$ and estimate error from scattering intensities. Initial calculations of the pair-distance probability distribution, $P(r)$, were conducted using a scan of the maximum molecule distance $D_{\max }$ using Python scripts (Lipfert et al. 2007) and GNOM (Svergun 1992) within the ATSAS analysis package (embl-hamburg.de/). $D_{\max }$ was determined based on a smooth plot of $P(r)$ where $D_{\max }$ corresponds to an abscissa intercept at $r=0$. The error in $D_{\max }$ is reported as the interval over which $D_{\max }$ results in a $P(r)$ function with a smooth intercept at $r=0$.

\section{Theoretical scattering calculations}

Coordinates were extracted from single frames of MD simulations and imported into CRYSOL (Svergun et al. 1995) where default parameters were selected. The calculated $R_{\mathrm{g}}$ and maximum molecular diameter excluding hydrogen volume were recorded. Theoretical intensities generated by CRYSOL (Svergun et al. 1995) were imported into GNOM (Svergun 1992) where the predicted maximum molecular diameter is input as $D_{\max }$. A scan of $P$ $(r)$, the pair distribution function, was performed at $D_{\max } \pm 5 \AA$ based on a smooth plot of $P(r)$ where $D_{\max }$ corresponds to an abscissa intercept at $r=0$. The error $R_{\mathrm{g}}$ calculated from theoretical scattering profiles generated from CRYSOL are not explicitly reported by GNOM due to the lack of experimental error in the scattering intensities. A 3\% error was calculated and added to the theoretical intensities. The error in $D_{\max }$ is reported as the interval over which $D_{\text {max }}$ results in a $P(r)$ function with a smooth intercept at $r=0$.

\section{SUPPLEMENTAL MATERIAL}

Supplemental material is available for this article.

\section{ACKNOWLEDGMENTS}

We would like to thank Dr. Kayleigh McGovern-Gooch and Abeer Ageeli for helpful discussions. We gratefully acknowledge use of the SAXS core facility of the Center for Cancer Research, National Cancer Institute ( $\mathrm{NCl}$ ). The shared scattering beamline 12-ID-B resource is allocated under the PUP-24152 agreement between the $\mathrm{NCl}$ and Argonne National Laboratory (ANL). We thank Dr. Lixin Fan (NCl) and Dr. Xiaobing Zuo (ANL) for their expert support. Use of the Advanced Photon Source, a US Department of Energy (DOE) Office of Science User Facility, was operated for the DOE Office of Science by ANL under contract no. DE-AC02-06CH11357. Support was also provided by University of the Sciences (to N.J.B.) and National Institutes of Health (K22-HL121113A to N.J.B.)

Received December 8, 2018; accepted May 13, 2019.

\section{REFERENCES}

Ageeli AA, McGovern-Gooch KR, Kaminska MM, Baird NJ. 2018. Finely tuned conformational dynamics regulate the protective function of the IncRNA MALAT1 triple helix. Nucleic Acids Res 47: 1468-1481. doi:10.1093/nar/gky1171

Arambula JF, Ramisetty SR, Baranger AM, Zimmerman SC. 2009. A simple ligand that selectively targets CUG trinucleotide repeats and inhibits MBNL protein binding. Proc Natl Acad Sci 106: 16068-16073. doi:10.1073/pnas.0901824106

Arun G, Diermeier SD, Spector DL. 2018. Therapeutic targeting of long non-coding RNAs in cancer. Trends Mol Med 24: 257-277. doi:10.1016/j.molmed.2018.01.001

Aytenfisu AH, Liberman JA, Wedekind JE, Mathews DH. 2015. Molecular mechanism for $\mathrm{preQ}_{1}-\|$ riboswitch function revealed by molecular dynamics. RNA 21: 1898-1907. doi:10.1261/rna .051367 .115

Baeyens KJ, De Bondt HL, Holbrook SR. 1995. Structure of an RNA double helix including uracil-uracil base pairs in an internal loop. Nat Struct Mol Biol 2: 56-62. doi:10.1038/nsb0195-56

Berendsen HJC, Postma JPM, van Gunsteren WF, DiNola A, Haak JR. 1984. Molecular dynamics with coupling to an external bath. $J$ Chem Phys 81: 3684-3690. doi:10.1063/1.448118

Brown JA, Valenstein ML, Yario TA, Tycowski KT, Steitz JA. 2012. Formation of triple-helical structures by the $3^{\prime}$-end sequences of MALAT1 and MEN $\beta$ noncoding RNAs. Proc Natl Acad Sci 109: 19202-19207. doi:10.1073/pnas.1217338109

Brown JA, Kinzig CG, DeGregorio SJ, Steitz JA. 2016. Hoogsteen-position pyrimidines promote the stability and function of the MALAT1 RNA triple helix. RNA 22: 743-749. doi:10.1261/rna .055707 .115

Case DA, Ben-Shalom IY, Brozell SR, Cerutti DS, Cheatham TE III, Cruzeiro WWD, Darden TA, Duke RE, Ghoreishi D, Gilson MK, et al. 2016. AMBER. University of California San Francisco, San Francisco.

Conrad NK, Steitz JA. 2005. A Kaposi's sarcoma virus RNA element that increases the nuclear abundance of intronless transcripts. EMBO J 24: 1831-1841. doi:10.1038/sj.emboj.7600662

Conrad NK, Mili S, Marshall EL, Shu M-D, Steitz JA. 2006. Identification of a rapid mammalian deadenylation-dependent decay pathway and its inhibition by a viral RNA element. Mol Cell 24: 943-953. doi:10.1016/j.molcel.2006.10.029

Dethoff EA, Hansen AL, Musselman C, Watt ED, Andricioaei I, AlHashimi HM. 2008. Characterizing complex dynamics in the transactivation response element apical loop and motional correlations with the bulge by NMR, molecular dynamics, and mutagenesis. Biophys J 95: 3906-3915. doi:10.1529/biophysj.108.140285

Donlic A, Morgan BS, Xu JL, Liu A, Roble C, Hargrove AE. 2018. Discovery of small molecule ligands for MALAT1 by tuning an RNA-binding scaffold. Angew Chem Int Ed Engl 57: 1324213247. doi:10.1002/anie.201808823

Galindo-Murillo R, Roe DR, Cheatham TE. 2015. Convergence and reproducibility in molecular dynamics simulations of the DNA duplex d(GCACGAACGAACGAACGC). Biochim Biophys Acta 1850: 1041-1058. doi:10.1016/j.bbagen.2014.09.007

Ganser LR, Lee J, Rangadurai A, Merriman DK, Kelly ML, Kansal AD, Sathyamoorthy B, Al-Hashimi HM. 2018. High-performance virtual screening by targeting a high-resolution RNA dynamic ensemble. Nat Struct Mol Biol 25: 425-434. doi:10.1038/s41594-018-0062-4

Garneau NL, Sokoloski KJ, Opyrchal M, Neff CP, Wilusz CJ, Wilusz J. 2008. The $3^{\prime}$ untranslated region of sindbis virus represses 
deadenylation of viral transcripts in mosquito and mammalian cells. J Virol 82: 880-892. doi:10.1128/JVI.01205-07

Geisler S, Lojek L, Khalil AM, Baker KE, Coller J. 2012. Decapping of long noncoding RNAs regulates inducible genes. Mol Cell 45: 279-291. doi:10.1016/j.molcel.2011.11.025

Hori N, Denesyuk NA, Thirumalai D. 2018. Frictional effects on RNA folding: speed limit and kramers turnover. J Phys Chem B. doi:10.1021/acs.jpcb.8b07129

Hua B, Panja S, Wang Y, Woodson SA, Ha T. 2018. Mimicking co-transcriptional RNA folding using a superhelicase. J Am Chem Soc 140: 10067-10070. doi:10.1021/jacs.8b03784

Huang W, Kim J, Jha S, Aboul-ela F. 2013. The impact of a ligand binding on strand migration in the SAM-I riboswitch. PLoS Comput Biol 9: e1003069. doi:10.1371/journal.pcbi.1003069

Huarte M. 2015. The emerging role of IncRNAs in cancer. Nat Med 21: 1253-1261. doi:10.1038/nm.3981

Humphrey W, Dalke A, Schulten K. 1996. VMD: visual molecular dynamics. J Mol Graph 14: 33-38. doi:10.1016/0263-7855(96)00018-5

Hyeon C, Thirumalai D. 2012. Chain length determines the folding rates of RNA. Biophys J 102: L11-L13. doi:10.1016/j.bpj.2012.01.003

Ji P, Diederichs S, Wang W, Böing S, Metzger R, Schneider PM, Tidow N, Brandt B, Buerger $H$, Bulk E, et al. 2003. MALAT-1, a novel noncoding RNA, and thymosin $\beta 4$ predict metastasis and survival in early-stage non-small cell lung cancer. Oncogene 22: 8031-8041. doi:10.1038/sj.onc. 1206928

Johnsson P, Morris KV. 2014. Expanding the functional role of long noncoding RNAs. Cell Res 24: 1284-1285. doi:10.1038/cr.2014.104

Kierzek R, Burkard ME, Turner DH. 1999. Thermodynamics of single mismatches in RNA duplexes. Biochemistry 38: 14214-14223. doi:10.1021/bi991186l

Lai M, Yang Z, Zhou L, Zhu Q, Xie H, Zhang F, Wu L, Chen L, Zheng S. 2012. Long non-coding RNA MALAT-1 overexpression predicts tumor recurrence of hepatocellular carcinoma after liver transplantation. Med Oncol 29: 1810-1816. doi:10.1007/s12032-011-0004-z

Leontis NB, Westhof E. 2001. Geometric nomenclature and classification of RNA base pairs. RNA 7: 499-512. doi:10.1017/S13558382 01002515

Lin R, Maeda S, Liu C, Karin M, Edgington TS. 2007. A large noncoding RNA is a marker for murine hepatocellular carcinomas and a spectrum of human carcinomas. Oncogene 26: 851-858. doi:10 .1038/sj.onc. 1209846

Lipfert J, Das R, Chu VB, Kudaravalli M, Boyd N, Herschlag D, Doniach S. 2007. Structural transitions and thermodynamics of a glycine-dependent riboswitch from Vibrio cholerae. J Mol Biol 365: 1393-1406. doi:10.1016/j.jmb.2006.10.022

Lu X-J, Olson WK. 2003. 3DNA: a software package for the analysis, rebuilding and visualization of three-dimensional nucleic acid structures. Nucleic Acids Res 31: 5108-5121. doi:10.1093/nar/gkg680

Lu X-J, Bussemaker HJ, Olson WK. 2015. DSSR: an integrated software tool for dissecting the spatial structure of RNA. Nucleic Acids Res 43: e142. doi:10.1093/nar/gkv716

Mahen EM, Harger JW, Calderon EM, Fedor MJ. 2005. Kinetics and thermodynamics make different contributions to RNA folding in vitro and in yeast. Mol Cell 19: 27-37. doi:10.1016/j.molcel.2005.05 .025

Mitton-Fry RM, DeGregorio SJ, Wang J, Steitz TA, Steitz JA. 2010. Poly(A) tail recognition by a viral RNA element through assembly of a triple helix. Science 330: 1244-1247. doi:10.1126/science .1195858

Muhlrad D, Parker R. 2005. The yeast EDC1 mRNA undergoes deadenylation-independent decapping stimulated by Not2p, Not4p, and Not5p. EMBO J 24: 1033-1045. doi:10.1038/sj.emboj.7600560

Priyakumar UD, MacKerell AD. 2010. Role of the adenine ligand on the stabilization of the secondary and tertiary interactions in the adenine riboswitch. J Mol Biol 396: 1422-1438. doi:10.1016/j .jmb.2009.12.024
R Core Team. 2018. R: a language and environment for statistical computing. R Foundation for Statistical Computing, Vienna, Austria. http://www.R-project.org/.

Réblová K, Lankaš F, Rázga F, Krasovska MV, Koča J, Šponer J. 2006. Structure, dynamics, and elasticity of free 16 s rRNA helix 44 studied by molecular dynamics simulations. Biopolymers 82: 504-520. doi:10.1002/bip.20503

Russell R, Zhuang X, Babcock HP, Millett IS, Doniach S, Chu S, Herschlag D. 2002. Exploring the folding landscape of a structured RNA. Proc Natl Acad Sci 99: 155-160. doi:10.1073/pnas.221593598

Ryckaert J-P, Ciccotti G, Berendsen HJ. 1977. Numerical integration of the cartesian equations of motion of a system with constraints: molecular dynamics of n-alkanes. J Comput Phys 23: 327-341. doi:10.1016/0021-9991(77)90098-5

Saldi T, Fong N, Bentley DL. 2018. Transcription elongation rate affects nascent histone pre-mRNA folding and $3^{\prime}$ end processing. Genes Dev 32: 297-308. doi:10.1101/gad.310896.117

Serganov A, Nudler E. 2013. A decade of riboswitches. Cell 152: 1724. doi:10.1016/j.cell.2012.12.024

Sheng J, Gan J, Soares AS, Salon J, Huang Z. 2013. Structural insights of non-canonical $U * U$ pair and Hoogsteen interaction probed with $\mathrm{Se}$ atom. Nucleic Acids Res 41: 10476-10487. doi:10.1093/nar/gkt799

Suresh G, Srinivasan H, Nanda S, Priyakumar UD. 2016. Ligand-induced stabilization of a duplex-like architecture is crucial for the switching mechanism of the SAM-III riboswitch. Biochemistry 55: 3349-3360. doi:10.1021/acs.biochem.5b00973

Svergun DI. 1992. Determination of the regularization parameter in indirect-transform methods using perceptual criteria. J Appl Crystallogr 25: 495-503. doi:10.1107/S0021889892001663

Svergun D, Barberato C, Koch MHJ. 1995. CRYSOL - a program to evaluate $\mathrm{X}$-ray solution scattering of biological macromolecules from atomic coordinates. J Appl Crystallogr 28: 768-773. doi:10 $.1107 /$ S0021889895007047

Thompson DM, Parker R. 2007. Cytoplasmic decay of intergenic transcripts in Saccharomyces cerevisiae. Mol Cell Biol 27: 92-101. doi:10.1128/MCB.01023-06

Tycowski KT, Shu M-D, Borah S, Shi M, Steitz JA. 2012. Conservation of a triple-helix-forming RNA stability element in noncoding and genomic RNAs of diverse viruses. Cell Rep 2: 26-32. doi:10 .1016/j.celrep.2012.05.020

Tycowski KT, Shu M-D, Steitz JA. 2016. Myriad triple-helix-forming structures in the transposable element RNAs of plants and fungi. Cell Rep 15: 1266-1276. doi:10.1016/j.celrep.2016.04.010

van Knippenberg PH, Hilbers CW. 1986. Structure and dynamics of RNA. Springer, Boston. doi:10.1007/978-1-4684-5173-3.

Wang Z, Day N, Trifillis P, Kiledjian M. 1999. An mRNA stability complex functions with poly(A)-binding protein to stabilize mRNA in vitro. Mol Cell Biol 19: 4552-4560. doi:10.1128/MCB.19.7.4552

Wickiser JK, Winkler WC, Breaker RR, Crothers DM. 2005. The speed of RNA transcription and metabolite binding kinetics operate an FMN riboswitch. Mol Cell 18: 49-60. doi:10.1016/j.molcel.2005.02.032

Wilusz JE, Freier SM, Spector DL. 2008. 3' end processing of a long nuclear-retained noncoding RNA yields a tRNA-like cytoplasmic RNA. Cell 135: 919-932. doi:10.1016/j.cell.2008.10.012

Wilusz JE, JnBaptiste CK, Lu LY, Kuhn C-D, Joshua-Tor L, Sharp PA. 2012. A triple helix stabilizes the $3^{\prime}$ ends of long noncoding RNAs that lack poly(A) tails. Genes Dev 26: 2392-2407. doi:10 $.1101 / \mathrm{gad} .204438 .112$

Woo CJ. 2018. The therapeutic targeting of long noncoding RNA. In RNA therapeutics, Vol. 27 of topics in medicinal chemistry (ed. Garner AL), pp. 207-235. Springer International Publishing, Cham, Switzerland.

Xia X, Piao X, Fredrick K, Bong D. 2014. Bifacial PNA complexation inhibits enzymatic access to DNA and RNA. Chembiochem 15: $31-$ 36. doi:10.1002/cbic.201300536 

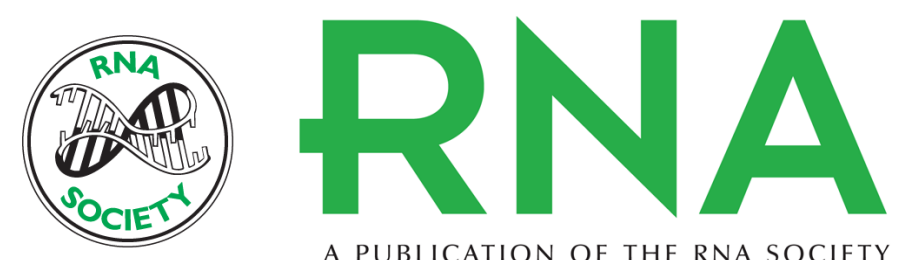

A PUBLICATION OF THE RNA SOCIETY

\section{A highly ordered, nonprotective MALAT1 ENE structure is adopted prior to triplex formation}

Michael J. Yonkunas and Nathan J. Baird

RNA 2019 25: 975-984 originally published online May 21, 2019

Access the most recent version at doi:10.1261/rna.069906.118

\section{Supplemental http://rnajournal.cshlp.org/content/suppl/2019/05/21/rna.069906.118.DC1 \\ Material}

References This article cites 53 articles, 12 of which can be accessed free at: http://rnajournal.cshlp.org/content/25/8/975.full.html\#ref-list-1

Creative This article is distributed exclusively by the RNA Society for the first 12 months after the Commons full-issue publication date (see http://rnajournal.cshlp.org/site/misc/terms.xhtml). After 12

License months, it is available under a Creative Commons License (Attribution-NonCommercial 4.0 International), as described at http://creativecommons.org/licenses/by-nc/4.0/.

Email Alerting
Service

Receive free email alerts when new articles cite this article - sign up in the box at the top right corner of the article or click here.

To subscribe to $R N A$ go to:

http://rnajournal.cshlp.org/subscriptions 